\title{
Efficiency of enhanced oil recovery by injection of low-salinity water in barium-containing carbonate reservoirs
}

\author{
Hyemin Park ${ }^{1}$ Yongjun Park ${ }^{1}$ Yeonkyeong Lee ${ }^{1} \cdot$ Wonmo Sung ${ }^{1}$
}

Received: 17 March 2018/ Published online: 16 July 2018

(C) The Author(s) 2018

\begin{abstract}
When low-salinity water containing sulfate ions is injected into carbonate reservoirs, rock dissolution and in situ precipitation occur, altering rock permeability and wettability. Particularly, when barium ions are present in formation water, they react chemically with $\mathrm{SO}_{4}^{2-}$, and $\mathrm{BaSO}_{4}$ is precipitated. These reactions can cause a serious impact on the efficiency of enhanced oil recovery (EOR). Therefore, the main purpose of this study was to identify EOR efficiency induced by lowsalinity waterflooding (LSWF) when $\mathrm{Ba}^{2+}$ is present in carbonate reservoirs. From the experimental results, it was confirmed that the permeability calculated by the measured pressure difference was improved because of rock dissolution predominating over in situ precipitation for the case of low $\mathrm{Ba}^{2+}$ concentrations. In the analysis of wettability alteration through the measurements of relative permeabilities before and after LSWF, the higher $\mathrm{Ba}^{2+}$ concentration case consumed more $\mathrm{SO}_{4}^{2-}$ in precipitating the $\mathrm{BaSO}_{4}$, resulting in weaker wettability alteration due to the reduction of sulfate activity. These phenomena ultimately influenced EOR efficiency, i.e., the oil recovery was greater for the lower $\mathrm{Ba}^{2+}$ concentration.
\end{abstract}

Keywords Low-salinity water flooding $\cdot$ Barium $\cdot$ Sulfate $\cdot$ Oil recovery $\cdot$ Carbonate

\section{Introduction}

A significant proportion of the world's oil is found in carbonate oil reservoirs. More than $80 \%$ of carbonate reservoirs have oil-wet or mixed wettability characteristics (Hawez and Ahmed 2014; Dong et al. 2017). Oil-wet systems typically have water breakthrough and high water production rates, which may result in high residual oil saturation. To improve oil recovery from carbonate reservoirs, wettability alteration is essential. One promising method to improve oil recovery is low-salinity waterflooding (LSWF). The mechanisms of LSWF proposed by various studies are summarized below. (1) Fines migration (Zeinijahromi and Bedrikovetsky 2015; Bedrikovetsky

Edited by Yan-Hua Sun

Yeonkyeong Lee

yglee1217@hanyang.ac.kr

$\triangle$ Wonmo Sung

wmsung@hanyang.ac.kr

1 Department of Earth Resources and Environmental Engineering, Hanyang University, 222 Wangsimni-ro, Seongdong-gu, Seoul 04763, Republic of Korea et al. 2015): clay becomes hydrated and swells as the salinity decreases, resulting in fines migration. As the clay moves, it changes the main flow path and improves the sweep efficiency. (2) Increased $\mathrm{pH}$ and reduced interfacial tension (IFT) effects (McGuire et al. 2005; Sohrabi et al. 2017): the $\mathrm{pH}$ increases during low-salinity injection due to desorption of cations. At high $\mathrm{pH}$ conditions, the organic acids of the crude oil generate soap, which reduces the oilwater IFT, similar to the effects of alkaline flooding. (3) Multiple component ion exchanges (MIE) (Lee et al. 2011; Kuznetsov et al. 2015): cation exchanges occur between clay mineral multivalent cations on the rock surface and fluid cations, releasing the adsorbed oil. (4) Wettability alteration (Shabib-Asl et al. 2015): the exchange of cations (in particular, potential-determining ions (PDIs): $\mathrm{Ca}^{2+}$, $\mathrm{Mg}^{2+}$, and $\mathrm{SO}_{4}^{2-}$ ) enhances the water wettability of the rock. (5) Mineral dissolution (Morrow and Buckley 2011): the surface of the carbonate rock dissolves and the oil film is peeled off by the low-salinity water. (6) Double-layer expansion (Kuznetsov et al. 2015): low-salinity water injection induces the electrical double layer to expand, reducing the attraction between the oil and pore surfaces.

For carbonate reservoir systems, which generally contain high-salinity formation water (FW) with a small 
amount of clay, the main mechanisms by which LSWF enhances oil recovery are wettability alteration by PDIs $\left(\mathrm{Ca}^{2+}, \mathrm{Mg}^{2+}\right.$, and $\left.\mathrm{SO}_{4}^{2-}\right)$ and rock dissolution (Mahani et al. 2015; Hiorth et al. 2010; Al-Shalabi et al. 2014). When the low-salinity water is injected into carbonate reservoirs, the negatively charged $\mathrm{SO}_{4}^{2-}$ ions in the injection water (IW) absorb onto the rock surface and decrease the positively charged surface potential of the rock. The reduced positive surface charge promotes co-adsorption of metal ions, such as $\mathrm{Ca}^{2+}$ and $\mathrm{Mg}^{2+}$, to the surface; these react with the adsorbed oil, promoting its release and improving oil recovery (Fig. 1). In addition, disruption of the chemical equilibria caused by injection of low-salinity water dissolves the carbonate rock surface, detaching the oil and further improving oil recovery. Since the salinity of the IW used in this study was constant at $35,197 \mathrm{ppm}$ of seawater, the electrical double-layer effect was not considered. Therefore, we mainly focused on the effect of chemical reactions on wettability alteration and investigated the chemical reactions associated with precipitation and dissolution.

In the $\mathrm{FW}$ of carbonate reservoirs, inorganic chemicals such as $\mathrm{Ba}^{2+}, \mathrm{Sr}^{2+}$, or $\mathrm{Fe}^{2+}$ ions are often present in a dissolved form. These ions exist at concentrations of 0-2100 ppm, according to an American Petroleum Institute (API) report (Neff and Sauer 1995). Barium $\left(\mathrm{Ba}^{2+}\right)$ is one of the most abundant inorganic chemicals present in the produced water of oil fields in the Gulf of Mexico and the North Sea. The API report highlights that dissolved $\mathrm{Ba}^{2+}$ is toxic to both marine biota and humans (Neff and Sauer 1995). When LSWF is applied to carbonate reservoirs, these ions can react with $\mathrm{SO}_{4}^{2-}$ ions and consequently form in situ precipitates such as $\mathrm{BaSO}_{4}$ and $\mathrm{SrSO}_{4}$, which are insoluble in the aqueous phase (Fig. 2). These precipitates build up in the pore network and reduce permeability, which can directly affect oil production. Merdhah and Yassin (2007) studied permeability reduction caused by $\mathrm{BaSO}_{4}$ precipitation in a sandstone core that had been completely saturated with water containing $\mathrm{Ba}^{2+}$ ions. Yuan and Todd (1991) used a simulation model to predict sulfate scale precipitation in a carbonate reservoir, without considering dissolution. They modeled simultaneous co-precipitation of $\mathrm{BaSO}_{4}, \mathrm{SrSO}_{4}$, and $\mathrm{CaSO}_{4}$, and the predicted scale precipitation was substantiated by field observations. Other studies of $\mathrm{CaSO}_{4}$ scale problems have shown that $\mathrm{SO}_{4}^{2-}$-rich injection solutions can generate $\mathrm{CaSO}_{4}$ and reduce the permeability of porous mediums (Sheikholeslami and $\mathrm{Ng}$ 2001; Moghadasi et al. 2003). To avoid precipitation-induced permeability reduction, Mahmoud (2014) applied chelating agents at various concentrations to prevent scale buildup by precipitation and to maintain the original permeability of the core sample. Meanwhile, Zahid et al. (2012) detected a pressure drop across a core sample and investigated permeability changes resulting from rock dissolution during low-salinity water injection; a significant increase in oil recovery was observed. Several researchers have focused on the effects of temperature and pressure on the dissolution of calcite, and the consequent effects of these changes on pH (Railsback 1993; Ouden et al. 2015; Peng et al. 2015). Previous studies of carbonate rock LSWF have focused either on rock dissolution of $\mathrm{Ca}^{2+}$ or $\mathrm{Mg}^{2+}$ or on precipitation of $\mathrm{CaSO}_{4}$. However, both these important chemical reactions dynamically affect the efficiency of wettability alteration, which emphasizes the need for an integrated understanding of these phenomena. In addition, there are no studies of the effect of $\mathrm{Ba}^{2+}$ ions, which react with sulfate ions to form insoluble precipitates.

In this study, we investigated the changes in permeability and wettability initiated by rock dissolution and in situ precipitation, in response to LSWF of carbonate reservoirs with $\mathrm{Ba}^{2+}$ in the $\mathrm{FW}$. Additionally, we examined the impact of $\mathrm{Ba}^{2+}$ concentrations on the enhanced oil recovery (EOR) efficiency of LSWF.

\section{Experimental}

\subsection{Rock and fluid properties}

The carbonate cores used in the experiments were Desert Pink rock from Edwards Plateau in Texas, USA. The
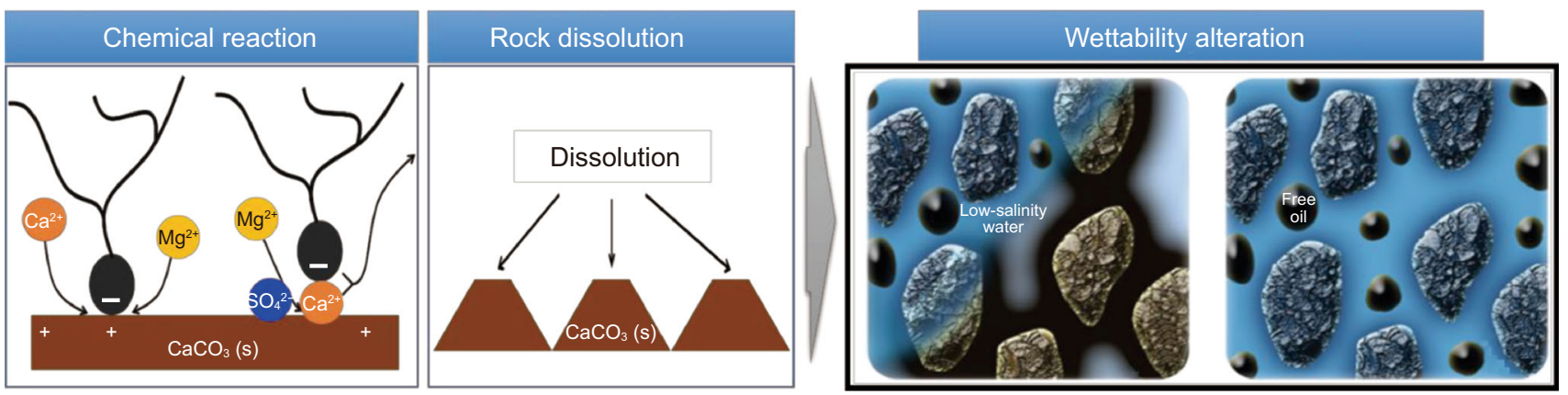

Fig. 1 Wettability alteration mechanisms of low-salinity waterflooding (LSWF) (RezaeiDoust et al. 2009; Hiorth et al. 2010) 


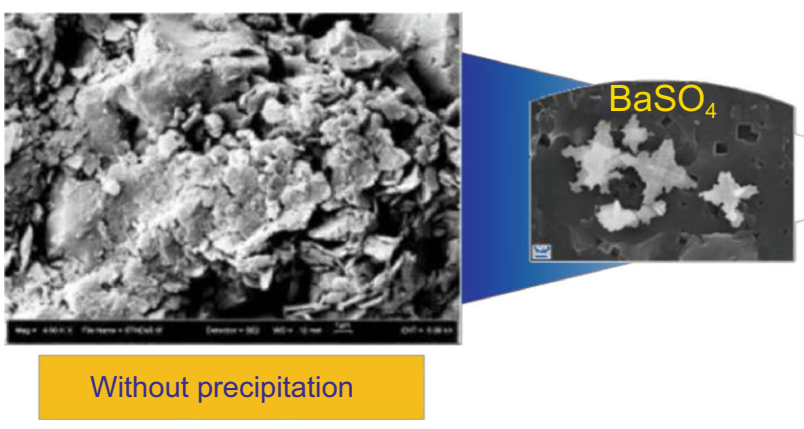

Fig. 2 In situ precipitation of $\mathrm{BaSO}_{4}$ in the reservoir

results of an X-ray diffraction (XRD) analysis, presented in Fig. 3, indicated that the Desert Pink core consisted of $99 \%$ $\mathrm{CaCO}_{3}$. The X-ray fluorescence (XRF) quantitative content analysis showed that the $\mathrm{Ca}^{2+}$ content was much higher than the $\mathrm{Mg}^{2+}$ content, implying that the core had not been dolomitized (Table 1). Based on the scanning electron microscope (SEM) image in Fig. 3, the $\mathrm{CaCO}_{3}$ crystals were almost spherical in shape, indicating calcite rather than needle-shaped aragonite. In Fig. 3, the X-ray computed tomography (CT) scanning result indicated a relatively homogeneous pore size and pore distribution. The reference properties of the Desert Pink cores, provided by the supplier, were porosity of $29 \%$ and permeability of 50 $\mathrm{mD}$. Based on the routine core analysis of six different Desert Pink cores, the porosity ranged from $22.9 \%$ to $31.0 \%$, and the permeability ranged from $26.8 \mathrm{mD}$ to 49.2 $\mathrm{mD}$ (Table 2). The crude oil used in this study originated from the Middle East and was relatively light with a specific gravity of $36.5^{\circ}$ API and an acid number of $0.29 \mathrm{mg} \mathrm{KOH} / \mathrm{g}$ (Table 3). In Table 4, the composition of the formation water (FW) and the $\mathrm{Ba}^{2+}$ concentration range were from the API report (Neff and Sauer, 1995). The low-salinity water used in this experimental study was synthetic seawater, with a salinity one quarter that of the FW. The seawater composition was based on information provided by Gupta et al. (2011).

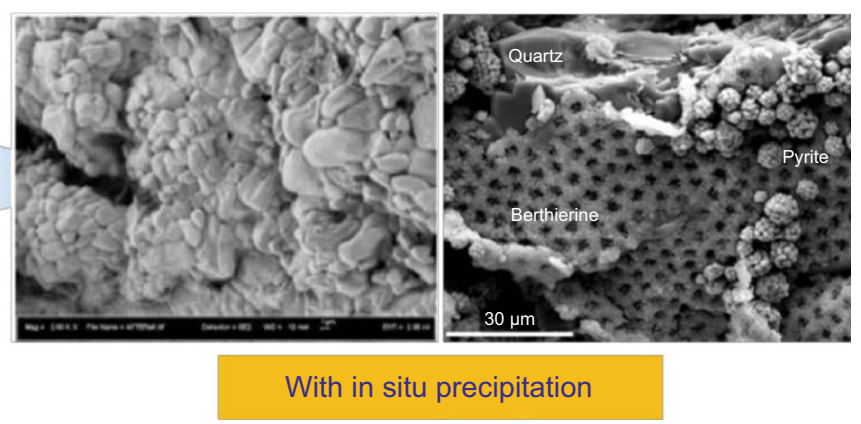

Table 1 X-ray fluorescence (XRF) results for mineral composition

\begin{tabular}{lllll}
\hline Component & $\mathrm{CaO}$ & $\mathrm{MgO}$ & $\mathrm{S}$ & L.O.I. \\
\hline Content, wt $\%$ & 55.4 & 0.27 & 0.05 & 44.18 \\
\hline
\end{tabular}

\subsection{Experimental apparatus and procedures}

The flooding apparatus was set up as shown in Fig. 4. The experimental system was heated to $130{ }^{\circ} \mathrm{C}$ using an electrical heating jacket. The produced fluids from the outlet port were collected and analyzed every 5 min to determine oil production and ion concentrations.

\subsubsection{Core flooding procedure}

A single carbonate sample set was one disk and two cores, which were saturated with FW. The disk was used for the initial contact angle measurement. One core was used for the initial relative permeability measurement, and the other core was used for the LSWF experiment and the postLSWF relative permeability measurement. A total of 6 disks and 12 cores were used for the experiment, with 6 different $\mathrm{Ba}^{2+}$ concentrations ranging from $0 \mathrm{ppm}$ to 2100 ppm, as listed in Table 2.
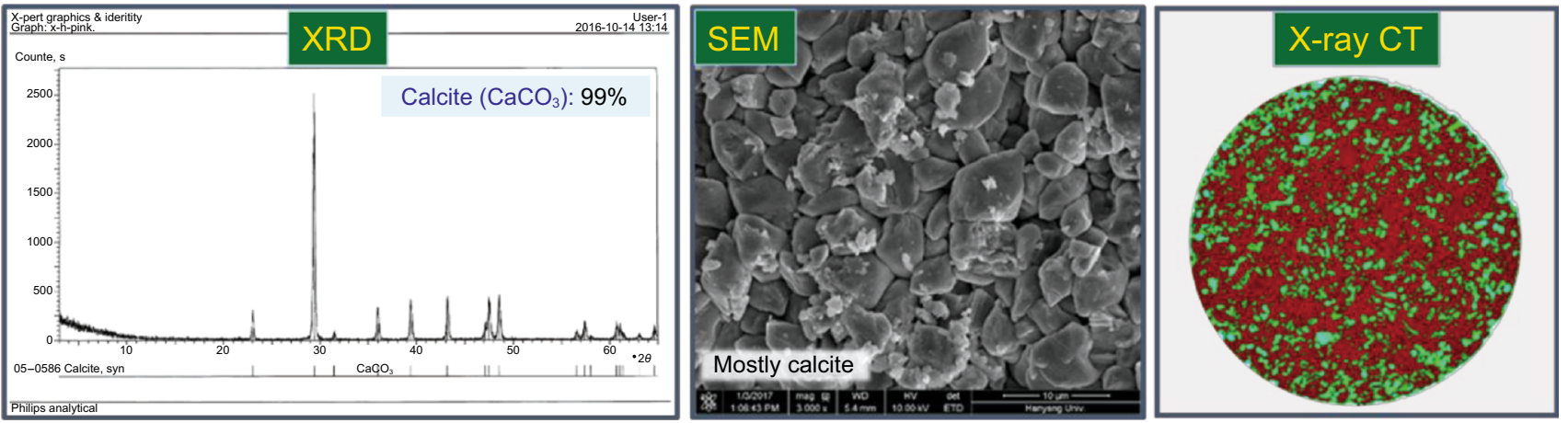

Fig. 3 X-ray diffraction (XRD) (a), scanning electron microscope (SEM) (b), and X-ray computed tomography (CT) (c) scanning results of the core 
Table 2 Results of the routine core analysis of Desert Pink cores

\begin{tabular}{lllll}
\hline Core samples & Pore volume, $\mathrm{cm}^{3}$ & Porosity, $\%$ & Permeability, $\mathrm{mD}$ & Case \\
\hline$\# 1$ & 42.0 & 30.0 & 48.0 & Ba000 \\
$\# 2$ & 36.0 & 25.4 & 31.0 & Ba300 \\
$\# 3$ & 34.0 & 31.0 & 49.2 & Ba600 \\
$\# 4$ & 22.9 & 31.3 & Ba900 \\
$\# 5$ & 32.0 & 24.3 & 26.8 & Ba1500 \\
$\# 6$ & 33.0 & 30.8 & 44.4 & Ba2100 \\
$\# 7$ & 38.0 & 21.0 & 33.0 & Ba000 \\
$\# 8$ & 29.2 & 25.8 & 24.2 & Ba300 \\
$\# 9$ & 36.0 & 24.2 & 30.1 & Ba600 \\
$\# 10$ & 34.1 & 26.5 & 33.0 & Ba900 \\
$\# 11$ & 37.0 & 24.3 & 26.7 & Ba1500 \\
$\# 12$ & 34.2 & 25.0 & 34.4 & Ba2100 \\
\hline
\end{tabular}

Table 3 Crude oil properties

\begin{tabular}{llllll}
\hline Oil gravity, ${ }^{\circ}$ API & Specific gravity & \multicolumn{2}{l}{ Viscosity, $\mathrm{cP}$} & Acid number, mg KOH/g & Base number, mg KOH/g \\
\cline { 2 - 5 } & & $40{ }^{\circ} \mathrm{C}$ & $130{ }^{\circ} \mathrm{C}$ & & 1.3 \\
\hline 36.5 & 0.84 & 3.032 & 1.028 & 0.29 & 1.3 \\
\hline
\end{tabular}

Table 4 Ionic composition and total dissolved solids (TDS) of the formation water and injection water

\begin{tabular}{lrrlllllllll}
\hline Water & \multicolumn{3}{c}{ Ionic composition, ppm } & & & & \multicolumn{3}{c}{ TDS, ppm } \\
\cline { 2 - 10 } & $\mathrm{Ca}^{2+}$ & $\mathrm{Mg}^{2+}$ & $\mathrm{Ba}^{2+}$ & $\mathrm{Sr}^{2+}$ & $\mathrm{Na}^{+}$ & $\mathrm{K}^{+}$ & $\mathrm{Cl}^{-}$ & $\mathrm{HCO}_{3}^{-}$ & $\mathrm{SO}_{4}^{2-}$ & \\
\hline Formation water & 6644 & 547 & $0-2100$ & 300 & 39,000 & - & 74,000 & - & - & 120,000 \\
Injection water & 521 & 1094 & - & - & 10,575 & 782 & 18,105 & 122 & 4000 & 35,197 \\
\hline
\end{tabular}

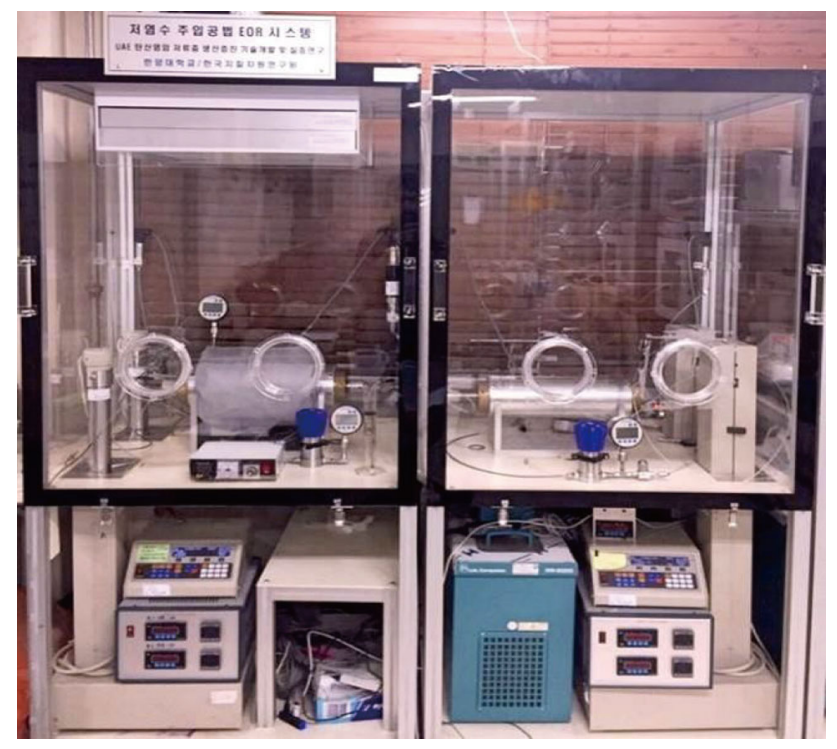

Fig. 4 Experimental system for LSWF

Before conducting the LSWF experiments, the porosity and permeability were measured. The cleaned and dried core was put in a Hassler core holder and fully saturated with FW. Thereafter, oil was injected until no further FW was produced from the core, to yield $S_{\mathrm{oi}}$ and $S_{\text {wir }}$. The core was soaked in oil in an aging cell at $130{ }^{\circ} \mathrm{C}$ for 4 weeks. The aged disk and aged core were used for the initial contact angle measurement and initial relative permeability measurement, according to the procedures described below. Another aged core was placed in a core holder, and the low-salinity waterflooding experiment was performed. Conventional waterflooding was conducted first, at a rate of $1 \mathrm{~cm}^{3} / \mathrm{min}$ until two pore volumes of water had been injected, followed by LSWF at the same rate for a further three pore volumes of injection (PVI).

\subsubsection{Relative permeability measurement}

In order to confirm the wettability alteration, relative permeability was measured before and after the low-salinity water injection. The unsteady state method, which is considered the most efficient laboratory method to measure 
relative permeability, was applied in this study (Honarpour and Mahmood 1988; Kim and Lee 2017).

Initial relative permeability $S_{\mathrm{oi}}$ and $S_{\mathrm{wir}}$ were measured after the core saturation process. The FW was injected into the carbonate core, which was fully saturated with oil, to reach $S_{\text {wir }}$ at a constant flow rate of $4 \mathrm{~cm}^{3} / \mathrm{min}$. The injection and production port pressures, and amount of produced fluid were recorded. Based on the Hafford method, the displacing fluid was injected at a high flow rate. Due to the high flow rate, the pressure difference of the experimental system was maintained above 20 psi, meaning that the influence of viscous forces exceeded capillarity influences, while restricting the pressure and saturation measurements to the inner sections of the cores, reducing capillary end effects (Honarpour and Mahmood 1988). The injection continued until no further oil was produced, to yield $S_{\text {or }}$.

Relative permeability after LSWF After LSWF was completed, the low-salinity water injection rate was increased to $4 \mathrm{~cm}^{3} / \mathrm{min}$ to calculate $S_{\text {or }}$. The oil was then injected until no more water was produced, to yield $S_{\text {wir }}$. After that, low-salinity water was injected at a constant rate of $4 \mathrm{~cm}^{3} / \mathrm{min}$, and the relative permeability was calculated based on the recorded pressure and produced fluid data.

\subsubsection{Contact angle measurement}

As an additional indicator to roughly confirm the wettability alteration, the contact angle measurement was also performed before and after the low-salinity water injection. The captive droplet method (Yousef et al. 2011) was used in this work. The dimensions of the core disk were $3.8 \mathrm{~cm}$ diameter $\times 1.3 \mathrm{~cm}$ length. To achieve the initial state $\left(S_{\text {oi }}\right.$ and $S_{\text {wir }}$ ), the disk was saturated with FW and crude oil and aged at the reservoir temperature for 4 weeks. The core disk was then submersed in the FW for $1 \mathrm{~h}$ to achieve chemical equilibrium. Then, an oil droplet $(10 \mu \mathrm{L})$ was dispensed beneath the core disk and analyzed. Measurements were repeated three times for each experiment, at room temperature. For measurement of the contact angle in the porous rock, the disks were first polished with six different grades of sandpaper to minimize the roughness effect (Al-Shaikh and Mahadevan 2016; Li et al. 2016). The standard deviation of the measurement was in the range of $0.13-0.21$, which indicates that the measured contact angles were relatively consistent. For porous media, the advancing angle should be measured during the dynamic contact angle test to avoid imbibition effects. Kwok et al. (1996) reported that the contact angle measured with the static contact angle test is the same as the angle measured with the dynamic test, according to Young's equation, if the measurement is captured at the moment that the oil droplet is formed on the rock surface.
Using a digital camera, we recorded a video immediately after the $10 \mu \mathrm{L}$ oil droplet was formed, and the moment that the oil droplet formed on the rock surface was captured by low-bond axisymmetric drop shape analysis (LBADSA) to determine the contact angle (Stalder et al. 2010).

\section{Results and discussion}

To investigate the effect of $\mathrm{Ba}^{2+}$ concentration on precipitation and dissolution during LSWF in carbonate reservoirs, several experiments were conducted with $\mathrm{Ba}^{2+}$ concentrations of 0-2100 ppm (Neff and Sauer 1995). In these experiments, conventional waterflooding was conducted for 2 PVI, followed by LSWF for another 3 PVI. The water was injected at a rate of $1 \mathrm{~cm}^{3} / \mathrm{min}$ to facilitate chemical reactions between the FW and IW. When lowsalinity water is injected into a carbonate reservoir containing $\mathrm{Ba}^{2+}$ ions, rock dissolution and in situ precipitation occur via the following chemical reactions:

$$
\begin{aligned}
& \mathrm{CaCO}_{3}(\mathrm{~s})+\mathrm{H}^{+}(\mathrm{IW}) \leftrightarrow \mathrm{Ca}^{2+}(\mathrm{aq})+\mathrm{HCO}_{3}^{-}(\mathrm{aq}) \\
& \mathrm{Ca}^{2+}(\mathrm{FW})+\mathrm{SO}_{4}^{2-}(\mathrm{IW}) \leftrightarrow \mathrm{CaSO}_{4}(\mathrm{~s}) \\
& \mathrm{Ba}^{2+}(\mathrm{FW})+\mathrm{SO}_{4}^{2-}(\mathrm{IW}) \leftrightarrow \mathrm{BaSO}_{4}(\mathrm{~s})
\end{aligned}
$$

The equilibrium constants for above chemical reaction are $6.53 \mathrm{E}+00,6.63 \mathrm{E}-06$, and $3.13 \mathrm{E}-10$, respectively. As low-salinity water is injected, the chemical equilibrium is disturbed, resulting in the dissolution of $\mathrm{Ca}^{2+}$ from calcite and anhydrite $\left(\mathrm{CaSO}_{4}\right)$ precipitation, which causes the change in permeability. Oil attached to the rock surface is released and wettability is altered. At the same time, $\mathrm{Ba}^{2+}$ ions in the $\mathrm{FW}$ react with $\mathrm{SO}_{4}^{2-}$ in the $\mathrm{IW}$, forming $\mathrm{BaSO}_{4}$ precipitates. These precipitates are insoluble and directly reduce the permeability. In this study, we investigated rock dissolution and in situ precipitation-induced permeability changes. The wettability alteration that occurred due to the chemical reactions shown above was also analyzed by measuring the contact angle and relative permeability before and after LSWF. Ultimately, we determined the LSWF EOR efficiency for carbonate reservoirs with $\mathrm{Ba}^{2+}$ in the FW.

\subsection{Changes in permeability}

As mentioned above, the experimental results showed that the calcite permeability changed when low-salinity water was injected. This change in permeability was due to rock dissolution and in situ precipitation (Alhuraishawy et al. 2018), which occurred via chemical reactions between divalent cations in the $\mathrm{FW}$, such as $\mathrm{Ba}^{2+}$ and $\mathrm{Ca}^{2+}$, and anions in the IW. As seen in Fig. 5, SEM images of thin 


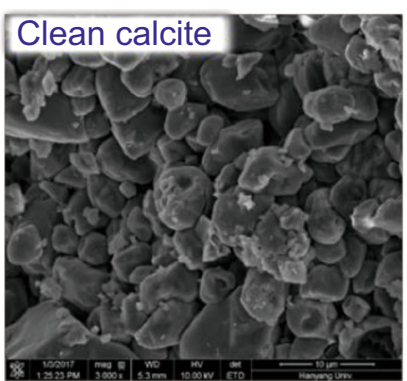

LSWF
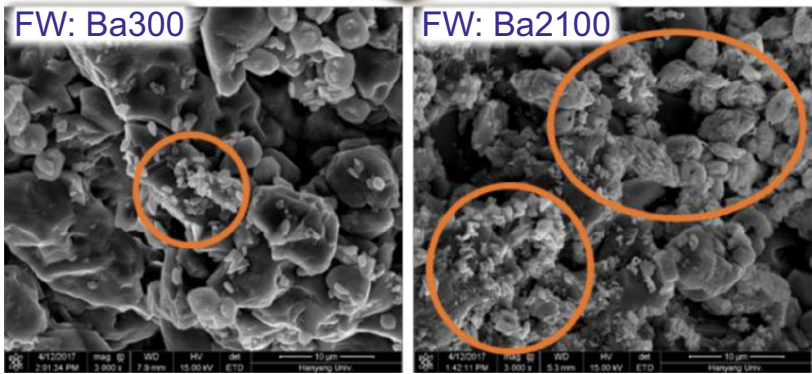

Fig. 5 SEM images of the calcite rock surface covered with $\mathrm{BaSO}_{4}$ precipitation

core sections illustrate that as the $\mathrm{Ba}^{2+}$ concentration increased, more precipitates formed, covering the rock surface more extensively. The concentration of $\mathrm{Ba}^{2+}$ and $\mathrm{Ca}^{2+}$ in the effluent was measured with inductively coupled plasma optical emission spectrometry (ICP-OES). As shown in Fig. 6, $\mathrm{Ba}^{2+}$ ions did not appear in the effluent after 3 PVI. This disappearance of $\mathrm{Ba}^{2+}$ occurred because the FW was displaced by the IW, and in situ precipitates occurred in the pore space. Additionally, the variation of

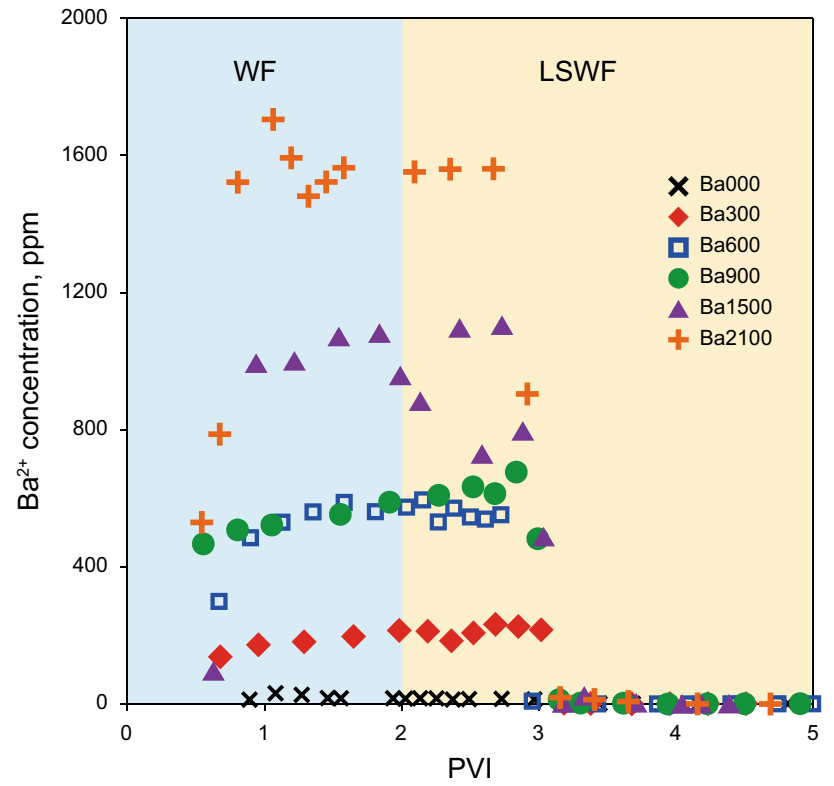

Fig. 6 Changes in $\mathrm{Ba}^{2+}$ concentration in the effluents
$\mathrm{Ca}^{2+}$ in the effluent, shown in Fig. 7, is thought to be caused by either calcite dissolution or $\mathrm{CaSO}_{4}$ precipitation. Based on the measured effluent concentrations, the amount of in situ precipitates and dissolved calcite was calculated from a mass balance of $\mathrm{Ba}^{2+}$ and $\mathrm{Ca}^{2+}$ ions in the core (Table 5). $\mathrm{Ba}^{2+}$ preferentially forms a precipitate with $\mathrm{SO}_{4}^{2-}$ due to its low solubility in water, and the amount of $\mathrm{BaSO}_{4}$ precipitate was calculated based on the $\mathrm{Ba}^{2+}$ concentration measured in the effluent. The calculated result shows that the higher the concentration of $\mathrm{Ba}^{2+}$ in the $\mathrm{FW}$, the more precipitate was formed. In the case of $2100 \mathrm{ppm}$ $\mathrm{Ba}^{2+}$, it was estimated that $3.035 \mathrm{~g}$ of precipitate was formed in the pore space, compared to $0.488 \mathrm{~g}$ in the $300 \mathrm{ppm} \mathrm{Ba}^{2+}$ condition. Meanwhile, when low-salinity water containing $\mathrm{SO}_{4}^{2-}$ was injected into the carbonate reservoir, either the $\mathrm{Ca}^{2+}$-containing minerals of the rock dissolved, or $\mathrm{CaSO}_{4}$ precipitated with $\mathrm{SO}_{4}^{2-}$. The amounts of dissolved calcite and $\mathrm{CaSO}_{4}$ precipitate were estimated based on a $\mathrm{Ca}^{2+}$ mass balance (Table 5). As the $\mathrm{Ba}^{2+}$ concentration increased from $300 \mathrm{ppm}$ to $2100 \mathrm{ppm}$, the $\mathrm{SO}_{4}^{2-}$ in the IW water reacted preferentially with $\mathrm{Ba}^{2+}$, leading to concomitant decreases in $\mathrm{SO}_{4}^{2-}$. Consequently, $\mathrm{Ca}^{2+}$-containing minerals dissolved more as the $\mathrm{Ba}^{2+}$ concentration increased. These phenomena affected the permeability of the core; accordingly, we investigated the permeability change during LSWF, using the measured pressure data as described below.

As previously described, the precipitation and dissolution reactions in the core induced a permeability change, and this change was calculated based on the measured pressure difference over the core plug between the

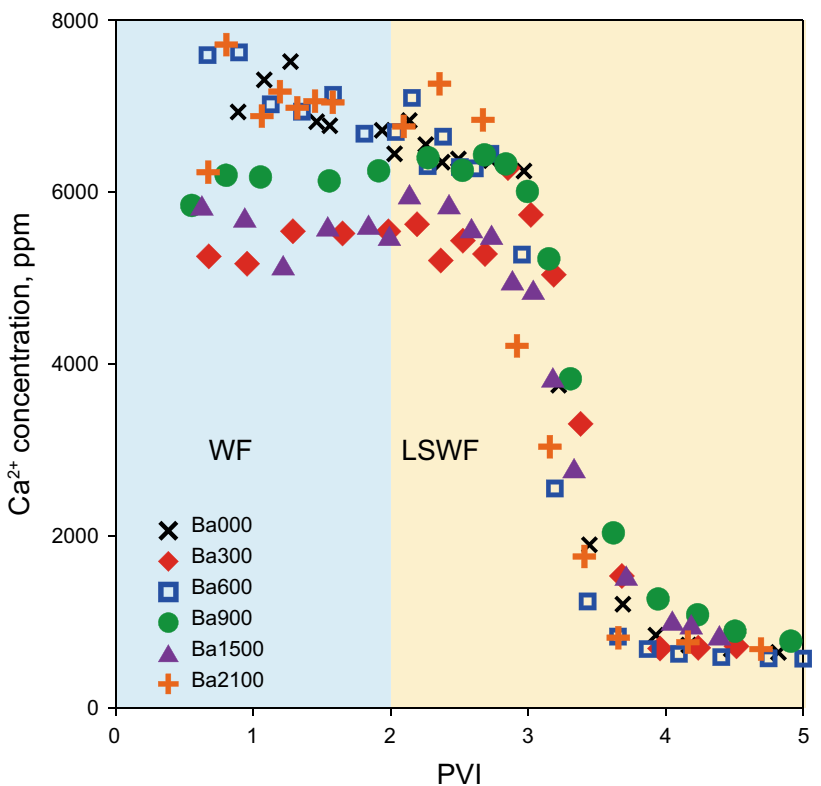

Fig. 7 Changes in $\mathrm{Ca}^{2+}$ concentrations in the effluents 
Table 5 The quantity of in situ precipitates and rock dissolution

\begin{tabular}{lll}
\hline Case & Insoluble precipitates $\left(\mathrm{BaSO}_{4}\right), \mathrm{g}$ & $\mathrm{Ca}^{2+}$-originated dissolution/precipitation, $\mathrm{g}$ \\
\hline Ba300 & 0.488 & -0.997 \\
Ba600 & 1.352 & -1.050 \\
Ba900 & 1.471 & -1.141 \\
Ba1500 & 2.096 & -1.805 \\
Ba2100 & 3.035 & -2.738 \\
\hline
\end{tabular}

Mass balance calculations (WF refers to conventional waterflooding, LSWF refers to low-salinity waterflooding, and IW refers to injection water; $\mathrm{Ba}^{2+}$ in $S_{\text {wi }}: \mathrm{Ba}^{2+}$ originally in initial water saturation, $\left(\mathrm{Ba}^{2+}\right.$ in IW) $)_{\mathrm{WF}}: \mathrm{Ba}^{2+}$ injected during conventional waterflooding, $\left(\mathrm{Ba}^{2+} \text { in effluents }\right)_{\mathrm{WF}}$ \& LSWF: $\mathrm{Ba}^{2+}$ produced during conventional waterflooding and low-salinity waterflooding):

$\mathrm{Ba}^{2+}$ change in the core $=\mathrm{Ba}^{2+}$ in $S_{\mathrm{wi}}+\left(\mathrm{Ba}^{2+} \text { in IW }\right)_{\mathrm{WF}}-\left(\mathrm{Ba}^{2+} \text { in effluents }\right)_{\mathrm{WF}}$ \& LSWF

$\mathrm{Ca}^{2+}$ change in the core $=\mathrm{Ca}^{2+}$ in $S_{\mathrm{wi}}+\left(\mathrm{Ca}^{2+} \text { in IW }\right)_{\mathrm{WF}}+\left(\mathrm{Ca}^{2+} \text { in IW }\right)_{\mathrm{LSWF}}-\left(\mathrm{Ca}^{2+}\right.$ in effluents) $)_{\mathrm{WF}} \&$ LSWF

injection and production ports (Fig. 8). In the calculation process, we used, as shown in Fig. 9, the permeability ratio between the changed and original permeability $\left(k_{\mathrm{c}} / k_{\mathrm{o}}\right)$, rather than the changed permeability itself $\left(k_{\mathrm{c}}\right)$. The ratio was used because the permeability of the calcite cores used in the flooding experiments ranged from $26.8 \mathrm{mD}$ to 49.2 $\mathrm{mD}$, as listed in Table 2. As shown in Fig. 9, in the cases of $\mathrm{Ba} 000(0 \mathrm{ppm})$ and $\mathrm{Ba} 300(300 \mathrm{ppm})$, the permeability ratio changed after LSWF. The resulting permeability was about 1.2 times greater than the initial permeability, because rock dissolution predominated over in situ precipitation. However, when a higher concentration of $\mathrm{Ba}^{2+}$ was present (600-2100 ppm), precipitation-inducing conditions reduced the permeability to almost 0.88 of the initial value.

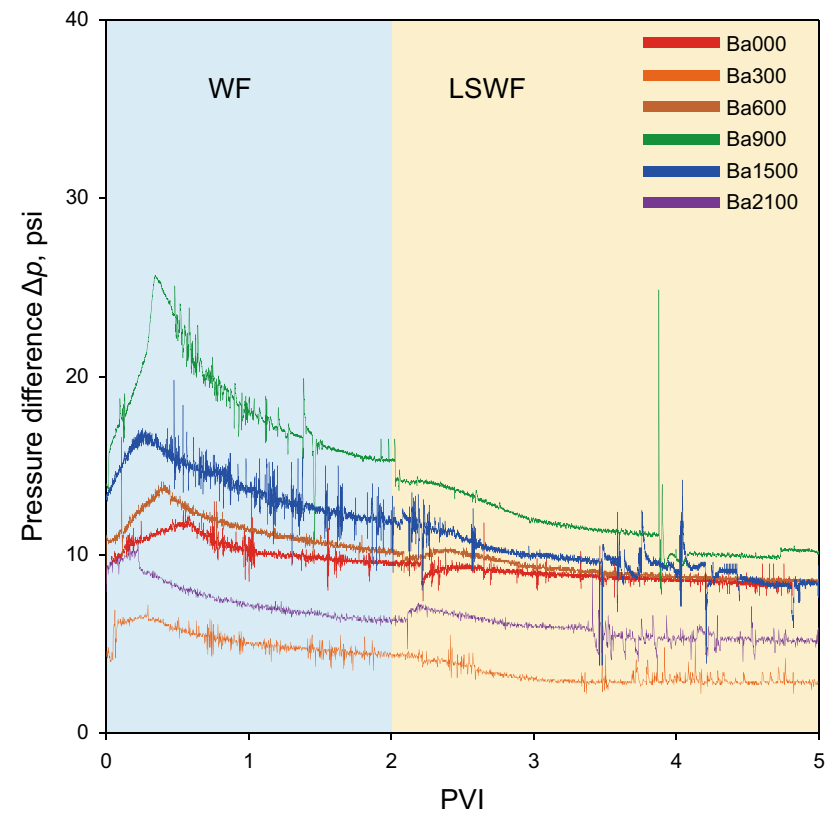

Fig. 8 Pressure difference between the injection and production ports

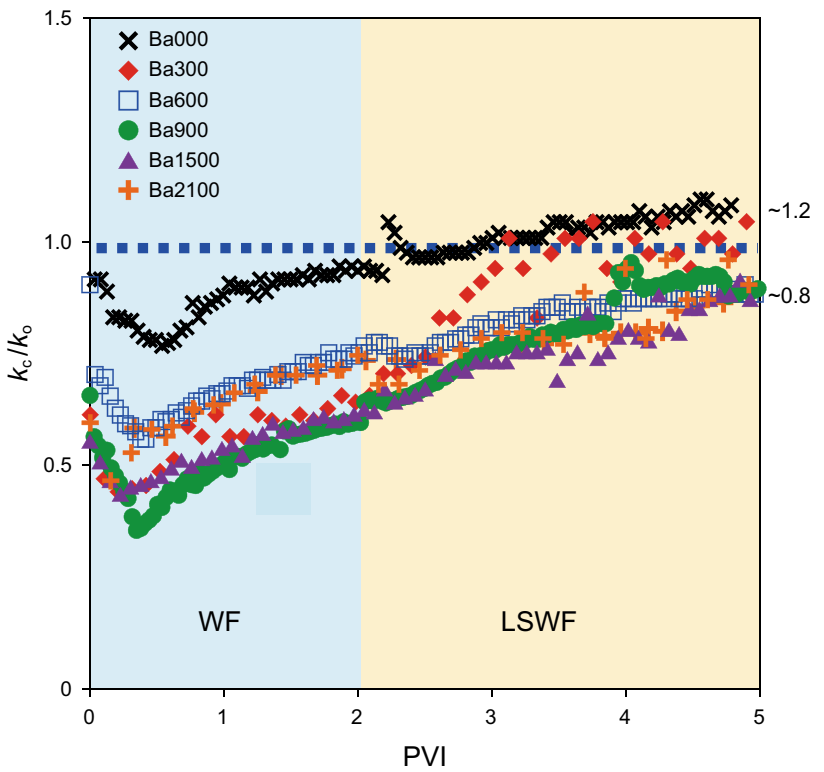

Fig. 9 Permeability changes caused by rock dissolution and in situ precipitation

As mentioned, rock dissolution and precipitation not only changed the permeability, but also affected the wettability, as discussed below.

\subsection{Wettability alteration}

To investigate the influence of $\mathrm{Ba}^{2+}$ precipitation on wettability, we first performed a contact angle analysis to quantitatively measure wettability alteration that occurred during LSWF. The contact angle indicates the wettability between the fluids and the rock, which is related to the IFT. The contact angles of the oil/brine/rock system were measured before and after LSWF. The results, depicted in Fig. 10, show that the initial wettability depended on the $\mathrm{Ba}^{2+}$ concentration and the contact angles ranged from $150.1^{\circ}$ to $140.8^{\circ}$, implying an oil-wet state. Our results are 


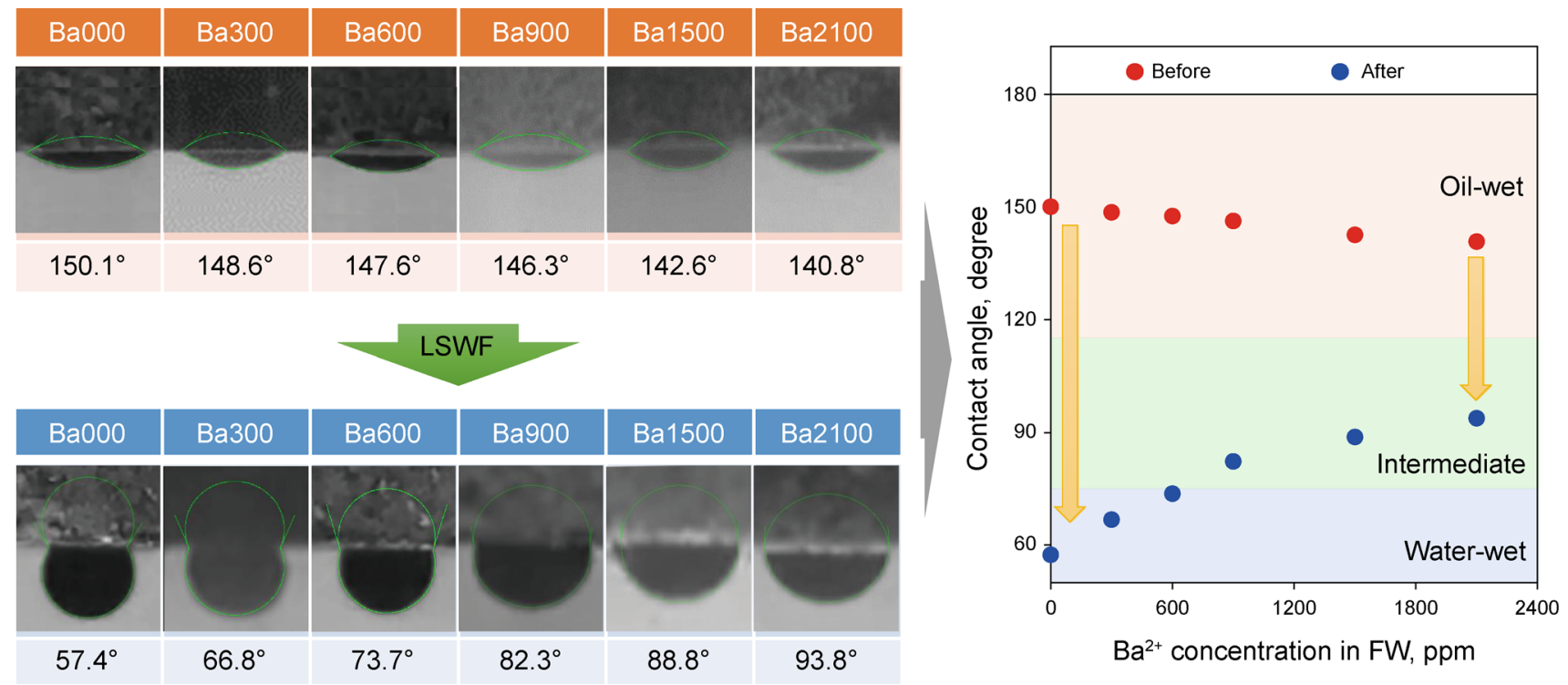

Fig. 10 Contact angle results showing wettability alterations after LSWF

similar to those of a previous study by Lagas et al. (1984), i.e., the lower the $\mathrm{Ba}^{2+}$ concentration in the $\mathrm{FW}$, the stronger the oil-wet characteristic of the rock. After LSWF was completed, the cores with pore precipitation were installed in the contact angle measurement apparatus and soaked in the IW, and the contact angles were measured. The contact angles after LSWF were reduced to a range of $57.4^{\circ}-93.8^{\circ}$, indicating water-wet to intermediate-wet conditions. As shown in Fig. 10, the greatest change in contact angle was observed in the case of $\mathrm{Ba} 000$, and as the $\mathrm{Ba}^{2+}$ concentration increased, the magnitude of the contact angle change decreased. This result can be attributed to the loss of $\mathrm{SO}_{4}^{2-}$, which was consumed as $\mathrm{BaSO}_{4}$ precipitated, resulting in reduced wettability alteration.

When carbonate rock properties change from oil wet to water wet, conditions become unfavorable to water flow, and the irreducible water saturation is increased, improving the oil flow ability. Accordingly, there is a change in the relative permeability of each fluid. The relative permeability was measured before and after LSWF to elucidate the flowing ability of the oil and IW. Figure 11 presents the relative permeability curves for the $\mathrm{Ba} 300$ and $\mathrm{Ba} 2100$ cases. Based on the results, at the same water saturation, there was almost no difference between the relative permeability oil curves for Ba300 and Ba2100. However, it was observed that after LSWF, these curves shifted to the right, and the oil relative permeability at the irreducible water saturation, $k_{\mathrm{ro}}\left(S_{\mathrm{wir}}\right)$, increased due to the altered wettability. The water relative permeability at maximum water saturation, $k_{\mathrm{rw}}\left(S_{\mathrm{wmax}}\right)$, decreased by $13.5 \%$ for Ba300, compared to $8.3 \%$ for Ba2100, meaning that the wettability was altered to a greater degree under low $\mathrm{Ba}^{2+}$ concentrations. This result concurs with those of the contact angle analysis mentioned previously.

As shown, $\mathrm{Ca}^{2+}$ mineral dissolution or $\mathrm{Ba}^{2+}$ precipitation yields not only permeability changes, but also alterations to the wettability of the carbonate rock. These effects can influence the EOR efficiency.

Figure 12 presents the oil recovery results for various $\mathrm{Ba}^{2+}$ concentrations. Conventional waterflooding was conducted for 2 PVI, followed by LSWF for 3 PVI. After completion of the conventional waterflooding, the oil recovery was $78.9 \%$ for the Ba2100 case, which was higher than the oil recovery achieved with Ba300 (77.4\%). When the $\mathrm{Ba}^{2+}$ concentration was lower, the wettability was more characteristic of oil-wet conditions after conventional waterflooding. However, during LSWF, the wettability characteristics became more water wet for lower $\mathrm{Ba}^{2+}$ concentrations, leading to additional oil recovery of $15.1 \%$ for the Ba300 case, compared to $8.9 \%$ for the Ba2100 case (Fig. 13). This result can be explained in terms of sulfate activity. That is, when $\mathrm{Ba}^{2+}$ ions were present in the $\mathrm{FW}$, the $\mathrm{SO}_{4}^{2-}$ ions contained in the IW reacted with the $\mathrm{Ba}^{2+}$ ions, causing $\mathrm{BaSO}_{4}$ precipitation. More $\mathrm{SO}_{4}^{2-}$ ions were involved in this chemical reaction as the $\mathrm{Ba}^{2+}$ concentration increased, which generated more precipitates. Ultimately, this phenomenon affected EOR efficiency. Therefore, when LSWF was applied to the carbonate reservoir, the EOR efficiency was limited when $\mathrm{Ba}^{2+}$ was present at concentrations of $300 \mathrm{ppm}$ or more in the FW. 


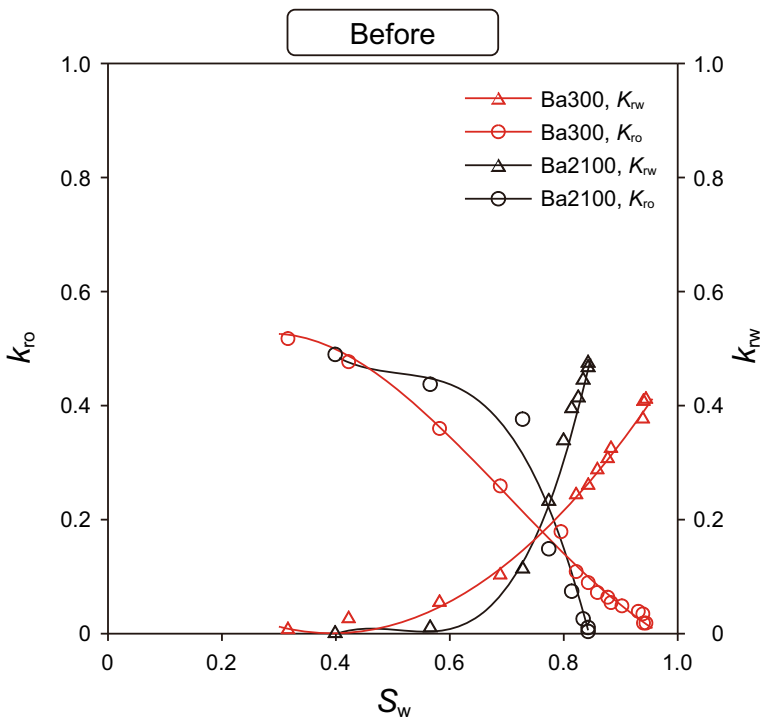

Fig. 11 Regressed relative permeability curves before and after LSWF

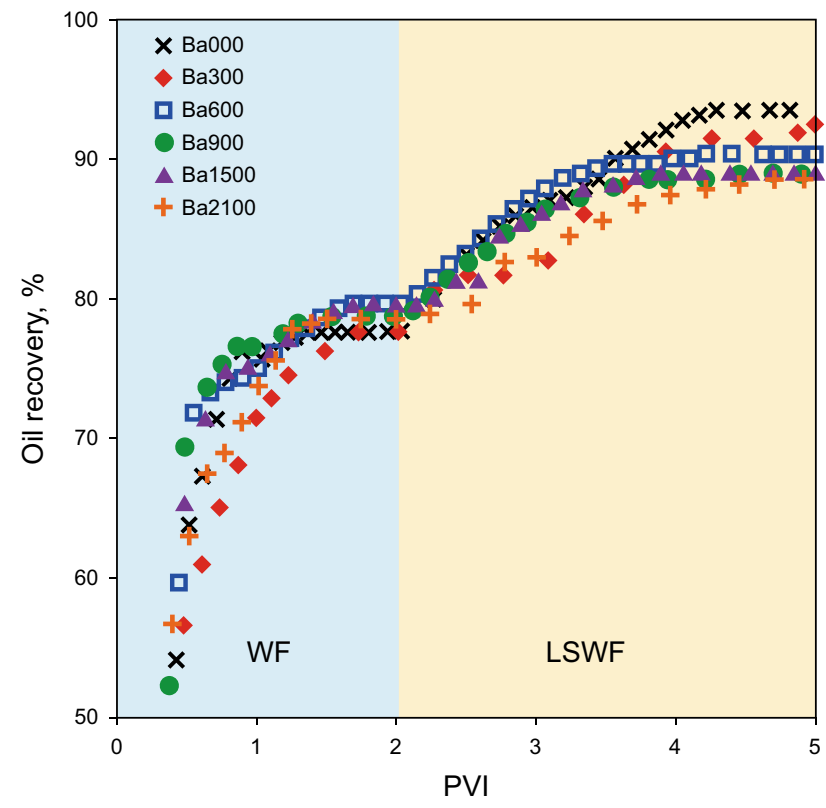

Fig. 12 Oil recovery results for conventional waterflooding followed by low-salinity waterflooding

\section{Summary and conclusions}

In this study, we investigated the effect of $\mathrm{Ba}^{2+}$ concentration on EOR efficiency by applying LSWF to a carbonate oil reservoir containing $\mathrm{Ba}^{2+}$ ions in the $\mathrm{FW}$.

It was revealed that $\mathrm{Ba}^{2+}$ preferentially formed $\mathrm{BaSO}_{4}$ precipitates with $\mathrm{SO}_{4}^{2-}$; thus, $\mathrm{Ba}^{2+}$ did not appear in the effluent after LSWF. Additionally, based on the effluent analysis, it was found that either $\mathrm{Ca}^{2+}$-containing minerals were dissolved or $\mathrm{CaSO}_{4}$ was precipitated with $\mathrm{SO}_{4}^{2-}$. These findings were confirmed by the measured pressure
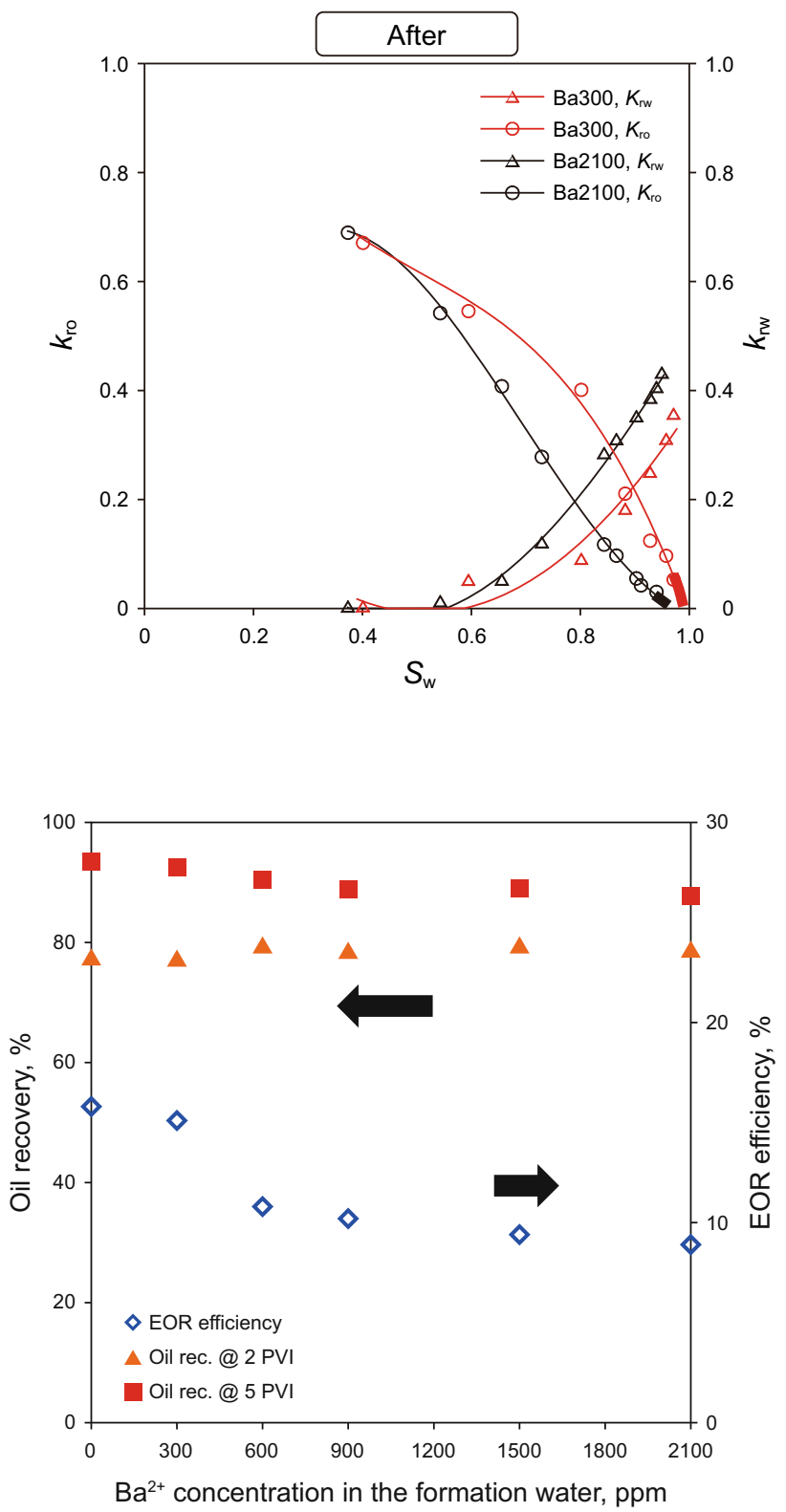

Fig. 13 Oil recovery and enhanced oil recovery (EOR) efficiency for various $\mathrm{Ba}^{2+}$ concentrations

results. Ultimately, when the $\mathrm{Ba}^{2+}$ concentration was low, the permeability improved because rock dissolution dominated in situ precipitation.

The results of contact angle measurements before and after LSWF confirmed that, as the $\mathrm{Ba}^{2+}$ concentration increased in the FW, wettability alteration was reduced. This result can be attributed to the reduction of sulfate activity. From the relative permeability measurements, it was confirmed that $S_{\text {wir }}$ increased and $k_{\mathrm{rw}}\left(S_{\mathrm{wmax}}\right)$ decreased, due to the wettability alteration of water-wet conditions after LSWF. In conclusion, the wettability was altered to a greater degree when the $\mathrm{Ba}^{2+}$ concentration in FW was low. 
The aforementioned effects consequently influenced the LSWF EOR efficiency; the oil recovery increased as the $\mathrm{Ba}^{2+}$ concentration decreased. Therefore, LSWF of carbonate oil reservoirs with IW containing $\mathrm{SO}_{4}^{2-}$ ions is not necessarily an appropriate EOR method when $\mathrm{Ba}^{2+}$ is present in the FW.

Acknowledgements This work was supported by a Grant as part of the "Development of IOR/EOR technologies and field verification for carbonate reservoirs in UAE" project by the Korean Government Ministry of Trade, Industry and Energy (MOTIE). (No. 20152510101980).

\section{Compliance with ethical standards}

Conflict of interest The authors declare that there is no conflict of interest regarding the publication of this article.

Open Access This article is distributed under the terms of the Creative Commons Attribution 4.0 International License (http://creative commons.org/licenses/by/4.0/), which permits unrestricted use, distribution, and reproduction in any medium, provided you give appropriate credit to the original author(s) and the source, provide a link to the Creative Commons license, and indicate if changes were made.

\section{References}

Alhuraishawy AK, Bai B, Wei M, Geng J, Pu J. Mineral dissolution and fine migration effect on oil recovery factor by low-salinity water flooding in low-permeability sandstone reservoir. Fuel. 2018;220:898-907. https://doi.org/10.1016/j.fuel.2018.02.016.

Al-Shaikh M, Mahadevan J. Impact of brine composition on calcite wettability: a sensitivity study. SPE J. 2016;21:1-214. https:// doi.org/10.2118/172187-PA.

Al-Shalabi EW, Sepehrnoori K, Delshad M. Mechanisms behind low salinity water injection in carbonate reservoirs. Fuel. 2014;121:11-9. https://doi.org/10.1016/j.fuel.2013.12.045.

Bedrikovetsky P, Zeinijahromi A, Badalyan A, Ahmetgareev V, Khisamov R. Fines-migration-assisted low-salinity water flooding: field case analysis. In: SPE Russian petroleum technology conference, 26-28 October, Moscow, Russia. 2015. https://doi. org/10.2118/176721-MS.

Dong P, Puerto M, Ma K, Mateen K, Ren G, Bourdarot G, et al. Lowinterfacial-tension foaming system for enhanced oil recovery in highly heterogeneous/fractured carbonate reservoirs. In: SPE international conference on oilfield chemistry, 3-5 April, Montgomery, Texas, USA. 2017. https://doi.org/10.2118/ 184569-MS.

Gupta R, Smith GG, Hu L, Willingham T, Lo Cascio M, Shyeh JJ, et al. Enhanced waterflood for carbonate reservoirs-impact of injection water composition. In: SPE Middle East oil and gas show and conference, 25-28 September, Manama, Bahrain. 2011. https://doi.org/10.2118/142668-MS.

Hawez $\mathrm{H}$, Ahmed Z. Enhanced oil recovery by $\mathrm{CO}_{2}$ injection in carbonate reservoirs. WIT Trans Ecol Environ. 2014;186:547-58. https://doi.org/10.2495/ESUS140481.

Hiorth A, Chthles LM, Madland MV. The impact of pore water chemistry on carbonate surface charge and oil wettability. Transp Porous Media. 2010;85:1-21. https://doi.org/10.1007/ s11242-010-9543-6.
Honarpour M, Mahmood SM. Relative-permeability measurements: an overview. J Pet Technol. 1988;40:963-6. https://doi.org/10. 2118/18565-PA.

Kim C, Lee J. Experimental study on the variation of relative permeability due to clay minerals in low salinity water-flooding. J Pet Sci Eng. 2017;151:292-304. https://doi.org/10.1016/j. petrol.2017.01.014.

Kuznetsov D, Cotterill S, Giddins MA, Blunt MJ. Low-salinity waterflood simulation: mechanistic and phenomenological models. In: SPE Asia Pacific enhanced oil recovery conference, 11-13 August, Kuala Lumpur, Malaysia. 2015. https://doi.org/ 10.2118/174615-MS.

Kwok DY, Lin R, Mui M, Neumann AW. Low-rate dynamic and static contact angles and the determination of solid surface tensions. Colloids Surf A. 1996;116:63-77. https://doi.org/10. 1016/0927-7757(96)03590-X.

Lagas P, Loch JPG, Bom CM, Gerringa LJA. The behavior of barium in a landfill and underlying soil. Water Air Soil Pollut. 1984;22:121-9. https://doi.org/10.1007/BF00163093.

Lee SY, Webb KJ, Collins IR, Lager A, Clarke SM, O’Sullivan M, et al. Low salinity oil recovery: increasing understanding of the underlying mechanisms of double layer expansion. In: IOR 2011-2016th European symposium on improved oil recovery, 12-14 April, Cambridge, UK. 2011. https://doi.org/10.2118/ 129722-MS

Li X, Abass H, Teklu TW, Cui Q. A shale matrix imbibition modelinterplay between capillary pressure and osmotic pressure. In: SPE annual technical conference and exhibition, 26-28 September, Dubai, UAE. 2016. https://doi.org/10.2118/181407-MS.

Mahani H, Keya AL, Berg S, Bartels WB, Nasralla R, Rossen WR. Insights into the mechanism of wettability alteration by lowsalinity flooding (LSF) in carbonates. Energy Fuel. 2015;29:1352-67. https://doi.org/10.1021/ef5023847.

Mahmoud M. Evaluating the damage caused by calcium sulfate scale precipitation during low- and high-salinity-water injection. J Pet Technol. 2014;53:141-50. https://doi.org/10.2118/164634-PA.

McGuire PL, Chatham JR, Paskvan FK, Sommer DM, Carini FH. Low salinity oil recovery: an exciting new EOR opportunity for Alaska's north slope. In: SPE western regional meeting, 30 March-1 April, Irvine, California. 2005. https://doi.org/10.2118/ 93903-MS.

Merdhah ABB, Yassin AAM. Barium sulfate scale formation in oil reservoir during water injection at high-barium formation water. J Appl Sci. 2007;7:2293-403. https://doi.org/10.3923/jas.2007. 2393.2403.

Moghadasi J, Jamialahmadi M, Steinhagen M. Scale formation in oil reservoir and production equipment during water injection (kinetics of $\mathrm{CaSO}_{4}$ and $\mathrm{CaCO}_{3}$ crystal growth and effect on formation damage). In: SPE European formation damage conference, 13-14 May, The Hague, Netherlands. 2003. https://doi.org/10.2118/82233-MS.

Morrow N, Buckley J. Improved oil recovery by low salinity waterflooding. J Pet Technol. 2011;63:106-12. https://doi.org/ 10.2118/129421-JPT

Neff JM, Sauer TC. Barium in produced water: fate and effects in the marine environment. API Publication 4633. Cambridge: American Petroleum Institute; 1995.

Ouden LD, Nasralla RA, Guo H, Bruining H, Van Kruijsdijk CPJW. Calcite dissolution behaviour during low salinity water flooding in carbonate rock. In: IOR 2015-2018th European symposium on improved oil recovery, 14-16 April, Dresden, Germany. 2015.

Peng C, Crawshaw JP, Maitland GC, Trusler JM. Kinetics of calcite dissolution in $\mathrm{CO}_{2}$-saturated water at temperatures between (323 and 373$) \mathrm{K}$ and pressures up to $13.8 \mathrm{MPa}$. Chem Geol. 
2015;483:74-85. https://doi.org/10.1016/j.chemgeo.2015.03. 012 .

Railsback LB. A thermodynamic perspective on the stability of carbonate minerals and its implications for carbonate petrology. J Geol Educ. 1993;41:1-12.

RezaeiDoust A, Puntervold T, Strand S, Austad T. Smart water as wettability modifier in carbonate and sandstone: a discussion of similarities/differences in the chemical mechanisms. Energy Fuels. 2009;23:4479-85. https://doi.org/10.1021/ef900185q.

Shabib-Asl A, Ayoub MA, Elraies KA. Laboratory investigation into wettability alteration by different low salinity water compositions in sandstone rock. In: SPE/IATMI Asia Pacific oil and gas conference and exhibition, 20-22 October, Bali, Indonesia. 2015. https://doi.org/10.2118/176492-MS.

Sheikholeslami $\mathrm{R}, \mathrm{Ng}$ M. Calcium sulfate precipitation in the presence of nondominant calcium carbonate: thermodynamics and kinetics. Ind Eng Chem Res. 2001;40:3570-8. https://doi. org/10.1021/ie000781c.

Sohrabi M, Mahzari P, Farzaneh SA, Mills JR, Tsoils P, Ireland S. Novel insights into mechanisms of oil recovery by low salinity water injection. SPE J. 2017;22:407-16. https://doi.org/10.2118/ 172778-MS.
Stalder AF, Melchior T, Muller M, Sage D, Blu T, Unser M. Lowbond axisymmetric drop shape analysis for surface tension and contact angle measurements of sessile drops. Colloids Surf A. 2010;364:72-81. https://doi.org/10.1016/j.colsurfa.2010.04.040.

Yousef AA, Al-Saleh SH, Al-Kaabi A, Al-Jawfi MS. Laboratory investigation of the impact of injection-water salinity and ionic content on oil recovery from carbonate reservoirs. SPE Reserv Eval Eng. 2011;14:578-93. https://doi.org/10.2118/137634-PA.

Yuan MD, Todd AC. Prediction of sulfate scaling tendency in oilfield operations. SPE Prod Eng. 1991;6:63-72. https://doi.org/10. 2118/18484-PA.

Zahid A, Shapiro A, Skauge A. Experimental studies of low salinity water flooding in carbonate reservoirs: a new promising approach. In: SPE EOR conference at oil and gas West Asia, 16-18 April, Muscat, Oman. 2012. https://doi.org/10.2118/ 155625-MS.

Zeinijahromi A, Bedrikovetsky P. Fines-migration-assisted oil and gas recovery (low salinity water injection). In: SPE Russian petroleum technology conference, 26-28 October, Moscow, Russia. 2015. https://doi.org/10.2118/176548-MS. 